\title{
0 que é ser educador infantil? 0 trabalho nas creches na perspectiva das educadoras'
}

\author{
Rodrigo Gabbi Polli \\ Rita de Cassia Sobreira Lopes
}

\section{RESUMO}

O presente estudo teve por objetivo investigar o que é ser educador infantil na perspectiva das educadoras. Foi utilizado um delineamento de estudo de caso coletivo. Participaram dessa pesquisa quinze educadoras de duas creches públicas federais de Porto Alegre/RS. As educadoras responderam a entrevistas, e as suas respostas foram examinadas através de análise de conteúdo qualitativa. Os resultados evidenciaram que um movimento de escolarização pode estar acontecendo em algumas Instituições de Educação Infantil do Brasil. Apesar disso, tanto o cuidar quanto o educar foram reconhecidos pelas educadoras como importantes, especialmente no trabalho com bebês. As profissionais não valorizaram apenas o cuidar ou o educar de forma excludente, mas pareceram buscar integrar as suas funções, o que reflete o momento de transição em que as creches se encontram. Por fim, destaca-se a importância de se pensar um novo modelo de atuação para as creches que contemple as especificidades dos bebês e das crianças pequenas.

Palavras-chave: bebês; comportamento de cuidado da criança; creches; desenvolvimento emocional; educadores infantis.

\section{ABSTRACT \\ What is it like to be an early childhood educator? The work in daycare in the perspective of educators}

This study aimed to investigate what it is like to be an early childhood educator in the perspective of the educators. A collective case study was conducted. Fifteen educators from two federal public daycare centers in Porto Alegre/RS participated in this research. The educators responded to interviews and their answers were examined through qualitative content analysis. The results showed that a movement of schooling may be happening in some Early Childhood Education Institutions in Brazil. Despite this, both care and education were recognized by the educators as important, especially working with babies. The professionals did not only value care or education in an exclusive way, but they seemed to seek to integrate their functions, which reflects the moment of transition in which daycare centers are. Finally, it is highlighted the importance of thinking about a new model for daycare centers that addresses the specificities of babies and young children.

Keywords: infants; child care; child day care; emotional development; early childhood educators.

Diversos estudos têm evidenciado uma cisão entre educar e cuidar nas Instituições de Educação Infantil, com uma valorização da atividade pedagógica e uma desvalorização da de cuidado (Elfer, 2007, 2015; Freitas \& Shelton, 2005), podendo esta última ser negligenciada ou realizada à custa da insatisfação das educadoras (Veríssimo \& Fonseca, 2003a, 2003b). Tal dicotomia pode ser vista dentro do funcionamento da creche, em que as atividades consi-

\section{Sobre os autores}

\section{R. G. P.}

http://orcid.org/0000-0002-

0017-5332

Universidade Federal do Rio

Grande do Sul - Porto Alegre, RS ropsiufsm@gmail.com

\section{R. C. S. L.}

http://orcid.org/0000-00026433-1648

Universidade Federal do Rio Grande do Sul - Porto Alegre, RS sobreiralopes@portoweb.com.br

\section{Direitos Autorais}

Este é um artigo de acesso aberto e pode ser reproduzido livremente, distribuído, transmitido ou modificado, por qualquer pessoa desde que usado sem fins comerciais. O trabalho é disponibilizado sob a licença Creative Commons CC-BY-NC.

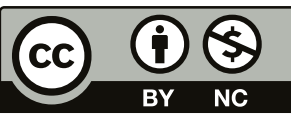

${ }^{1}$ Esse artigo é derivado da tese do primeiro autor, orientada pela segunda autora. 


\section{M." INTERACÃO EM PSICOLOGIA}

deradas pedagógicas são desempenhadas pelas professoras - as quais possuem uma maior formação - e os cuidados físicos são realizados pelas monitoras, assistentes ou auxiliares - com menor escolaridade (Lordelo \& Carvalho, 2003; Vitta \& Emmel, 2004). Essa divisão de trabalho, em que os profissionais com maior escolaridade são responsáveis pelo desenvolvimento de competências nas crianças, pode conduzir à ideia de que para lidar com os demais aspectos destas não seria necessária formação especializada (Lordelo \& Carvalho, 2003). Dessa forma, o trabalho direto com as crianças, em especial com bebês e crianças pequenas, pode ser visto com status inferior, em particular quando envolve cuidados físicos, como trocar fraldas e dar banho (Elfer \& Dearnley, 2007).

No Brasil, tal dicotomia entre cuidar e educar presente no atendimento à criança pequena - identificada também em outros países, como nos Estados Unidos (Freitas \& Shelton, 2005; Freitas et al., 2008) e na Inglaterra (Elfer, 2007; Elfer \& Dearnley, 2007) - decorre de uma diferença, desde suas origens, entre os serviços oferecidos às crianças de camadas populares e os destinados às crianças de camadas mais abastadas da população. As primeiras creches foram criadas para atender aos filhos de pais trabalhadores, isto é, as crianças provenientes de famílias pobres, e tinham por objetivo o "cuidado" - alimentação, proteção, higiene e manter as crianças fora das ruas. Por outro lado, os jardins de infância, instituições destinadas às crianças de famílias ricas, visavam à educação, à socialização e ao desenvolvimento (Freitas \& Shelton, 2005; Freitas et al., 2008).

Quando o atendimento à primeira infância passou a objetivar a promoção de uma educação compensatória, a função educativa foi introduzida pela primeira vez nas creches e pré-escolas, preparando as crianças provenientes das camadas sociais mais baixas para o colégio e a alfabetização, com o intuito de diminuir o fracasso escolar. Entretanto, os programas voltados à infância procuravam compensar carências não só educacionais, mas também sociais, culturais, afetivas, nutricionais e sanitárias das crianças oriundas de camadas populares. Com isso, ocorreu um predomínio da função assistencialista dentro das instituições pré-escolares, priorizando ações destinadas à saúde, alimentação e medicação (Freitas \& Shelton, 2005; Freitas et al., 2008).

Atualmente no Brasil, a criança tem por lei direito ao cuidado e à educação desde o seu nascimento (Presidência da República, Casa Civil, Subchefia para Assuntos Jurídicos, 1996) e, apesar do crescente número de bebês e crianças que frequentam creches e pré-escolas, um sistema integrado ainda não foi alcançado no Brasil (Freitas et al., 2008). Nesse sentido, pesquisadores da área têm destacado a importância de tratar cuidar e educar como inseparáveis (Elfer, 2007; Freitas \& Shelton, 2005; Freitas et al., 2008), sendo esta necessária integração uma das especificidades das Instituições de Educação Infantil (Monção, 2015). Ao mesmo tempo, é imprescindível reconceitualizar o cuidado de forma que este não seja reduzido ao atendimento das necessidades básicas da criança, mas, de outro modo, promova o seu desenvolvimento integral, nos mais diversos aspectos (Freitas \& Shelton, 2005). Cabe ainda destacar que o educar igualmente não deve ser reduzido à escolarização. Desse modo, a Educação Infantil difere das escolas, as quais, por estarem voltadas para esse fim, não são adequadas para atender às necessidades de bebês e crianças pequenas (Cerisara, 1999).

Hoje em dia, a partir da mudança do atendimento à criança de zero a seis anos do campo da Assistência Social para o da Educação (Dahlberg et al., 2001; Lordelo \& Carvalho, 2003), tem se assistido ao combate e à crítica ao modelo assistencialista, o qual caracterizou o serviço da creche desde suas origens. Tal crítica tem sido feita principalmente por meio da ênfase do papel educativo das Instituições de Educação Infantil (Monção, 2015; Veríssimo \& Fonseca, 2003b), o que pode incorrer em reducionismo ao excluir ou atribuir menor importância ao cuidar - rejeitando papéis inerentes à creche -, e acarretar atenção parcializada por não possibilitar a construção de um projeto de atendimento integral à infância (Veríssimo \& Fonseca, 2003a).

Ao mesmo tempo, o destaque do aspecto educativo também tem levado à aplicação na Educação Infantil de um modelo proveniente das instituições escolares. A tentativa de se reproduzir esse modelo pode ser percebida no funcionamento da creche, na organização do ambiente e na formação dos funcionários. Por exemplo, os espaços onde as crianças permanecem geralmente são organizados como salas de aula, com mesas, cadeiras, quadro e giz, sendo que a maioria das atividades realizadas pelas crianças é de caráter acadêmico, envolvendo papel e lápis. A partir disso, é possível perceber um movimento de escolarização de creches e pré-escolas, o qual enfatiza o desenvolvimento cognitivo sem o relacionar com os demais aspectos do desenvolvimento da criança (Lordelo \& Carvalho, 2003). Contudo, esse movimento de escolarização, caracterizado pela implantação na Educação Infantil de modelos de ensino-aprendizagem provenientes de instituições escolares e pela ênfase da função educativa de creches e pré-escolas (Elfer, 2015; Lordelo \& Carvalho, 2003; Monção, 2015), pode se mostrar inadequado quando transposto para o trabalho com bebês e crianças pequenas.

Conforme o que foi apresentado, as funções da creche têm sido alvo de discussão ao longo dos últimos anos, reflexo da fase transitória em que ela se encontra. Tal fato também se justifica frente ao aumento significativo do número de bebês e crianças que frequentam Instituições de Educação Infantil (Freitas et al., 2008; Instituto Nacional de Estudos e Pesquisas Educacionais Anísio Teixeira - INEP, 2014) e a importância de se promover um atendimento de qualidade nos servi- 


\section{MLE INTERACÃO EM 2. PSICOLOGIA}

ços voltados à infância. Nesse sentido, a literatura aponta a necessidade de se articular cuidar e educar com o intuito de disponibilizar à criança uma atenção integral que facilite o seu desenvolvimento. Assim, para que a atenção destinada aos bebês e às crianças pequenas dê conta de todos os aspectos que compreendem o seu crescimento e maturação, tanto o educar quanto o cuidar devem permear todo o processo que contempla a Educação Infantil. Ao mesmo tempo, é indispensável uma reconceitualização do cuidado de modo que este não se encontre limitado ao atendimento das necessidades básicas das crianças, mas promova o seu crescimento integral nos mais diversos âmbitos. Nesse contexto, o entendimento de cuidado conforme proposto por Donald Winnicott pode ser de grande valia.

Para que o bebê se desenvolva de maneira saudável, é preciso que alguém se dedique à tarefa de cuidar dele (Winnicott, 1987/2006). Isso se deve ao estado de dependência absoluta em que os bebês se encontram no começo de suas vidas (Winnicott, 1969/1994, 1987/2006). Se o ambiente for bem-sucedido em se adaptar a esse estado em que o bebê se encontra, esse por sua vez será capaz de confiar no ambiente. Isso é importante porque o desenvolvimento saudável da criança só ocorre em um contexto confiável, o qual decorre do fato de ela ser cuidada. Nesse sentido, é fundamental que o adulto responsável por cuidar do bebê estabeleça com ele um relacionamento estável e contínuo, respeitando e atendendo às suas necessidades (Winnicott, 1987/2006). Aqui, cabe destacar que a noção de cuidado vai além de atender às necessidades do corpo de fome, sono e higiene. 0 cuidar também abrange toda uma gama de necessidades mais sutis e emocionais, que só podem ser satisfeitas através de um contato humano (Winnicott, 1969/1994, 1987/2006).

Uma vez que os bebês e as crianças pequenas apresentam necessidades específicas relacionadas ao período de desenvolvimento inicial e primitivo pelo qual estão passando (Winnicott, 1969/1994, 1987/2006), essas necessidades, próprias da natureza humana, precisam ser contempladas independentemente do ambiente em que eles se encontram - seja em casa ou na creche. Tendo em vista que, quando o bebê começa a frequentar a creche, os educadores assumem uma dupla função, sendo eles responsáveis tanto por cuidar das crianças como por educá-las (Veríssimo \& Fonseca, 2003a; Vitta \& Emmel, 2004), é importante escutá-los nessa árdua e desafiadora tarefa. Nesse sentido, o presente estudo teve por objetivo investigar o que é ser educador infantil na perspectiva das educadoras.

\section{MÉTODO}

\section{PARTICIPANTES}

Participaram deste estudo quinze educadoras de duas creches públicas federais de Porto Alegre/RS - uma pertencente a uma universidade e outra a um hospital. Das quinze educadoras, seis trabalhavam na creche do hospital, e nove, na creche da universidade. Todas as educadoras são do sexo feminino, com idades entre 21 e 50 anos, e nível de escolaridade entre ensino médio incompleto e pós-graduação completa. Todas as educadoras possuíam experiência de trabalho com bebês e crianças pequenas da faixa etária dos quatro meses até os cinco anos de idade, faixa etária que compreende o período da Educação Infantil no Brasil, foco de interesse do presente estudo. As participantes foram selecionadas de um estudo maior, intitulado "Impacto da creche no desenvolvimento socioemocional e cognitivo infantil: estudo longitudinal do sexto mês de vida do bebê ao final dos anos pré-escolares" - CRESCI (Piccinini et al., 2012). O CRESCI está registrado na Plataforma Brasil sob protocolo CAAE 15840313.0.0000.5334.

\section{PROCEDIMENTOS E INSTRUMENTOS}

Para fins do presente estudo, foi utilizado um delineamento de estudo de caso coletivo (Stake, 1994), de caráter transversal. Para Stake (1994), o estudo de caso coletivo busca investigar e compreender um dado fenômeno, população ou condição através da pesquisa de vários casos conjuntamente. Os casos são escolhidos porque se acredita que o seu estudo permitirá uma melhor compreensão ou teorização sobre um conjunto ainda maior de casos. 0 interesse não recai sobre um caso particular, mas se estende a vários casos para possibilitar, pela comparação, conhecimentos mais profundos sobre o fenômeno em questão. Assim, não se enfatiza cada caso, mas sim particularidades e semelhanças sobre o tema.

De acordo com os procedimentos do projeto CRESCI, as educadoras foram contatadas nas escolas de Educação Infantil. Nessa ocasião, a pesquisa foi apresentada para as profissionais responsáveis pelos berçários, e as mesmas foram convidadas a participar do estudo e, no caso de aceite, assinaram o Termo de Consentimento Livre e Esclarecido. 0 projeto de pesquisa também foi apresentado à coordenação das escolas de Educação Infantil, e foi autorizada a realização da pesquisa nas instituições. A coleta de dados - desenvolvida no ano de 2011 - foi realizada em visita à creche, momento em que as educadoras responderam à Entrevista sobre a experiência e formação das educadoras e à Entrevista de crenças das educadoras sobre infância e adaptação do bebê à creche. 


\section{H MTERAC̄OOEM ET PSICOLOGIA}

\section{CONSIDERAÇÕES ÉTICAS}

O projeto CRESCl, do qual o presente estudo faz parte, foi aprovado pelo Comitê de Ética em Pesquisa da Universidade Federal do Rio Grande do Sul (Protoc. N²010070) e pelo Comitê de Ética do Hospital de Clínicas de Porto Alegre (Protoc. $\mathrm{N}^{\circ}$ 100553), sendo considerado ética e metodologicamente adequado, de acordo com a Resolução 510/2016 do Conselho Nacional de Saúde.

\section{ANÁLISE DOS DADOS}

As respostas das educadoras às entrevistas foram examinadas através de análise de conteúdo qualitativa (Laville \& Dionne, 1999). Num primeiro momento, as verbalizações de cada educadora foram analisadas separadamente, sendo avaliado o que a profissional trouxe e comunicou através da sua fala. Posteriormente, foi realizada uma análise de todas as educadoras de forma conjunta, sendo enfocado o que aparecia com maior intensidade e frequência, portanto, o que era comum e se repetia nas respostas dadas às entrevistas. Através da análise dos dados coletados, foram estabelecidas as categorias a serem trabalhadas. A estrutura de categorias utilizada foi oriunda, portanto, dos próprios dados e é constituída de quatro categorias de análise, a saber: a) eu como educadora, b) o que é ser educador infantil, c) crenças sobre bebês e crianças pequenas e d) o trabalho na creche. Em cada categoria de análise, utilizaram-se subcategorias provenientes também dos próprios dados. Nesse artigo, será apresentada uma subcategoria, a saber: educar e cuidar, a qual integra a categoria o que é ser educador infantil. A subcategoria foi ilustrada com verbalizações das educadoras. Buscando manter o seu anonimato, elas foram identificadas através de uma sigla (EH - Educadora Hospital; EU - Educadora Universidade) e de um número.

\section{RESULTADOS E DISCUSSÃO}

\section{EDUCAR E CUIDAR}

As educadoras que participaram do estudo referiram o educar e o cuidar como funções por elas desempenhadas na creche. Por um lado, pôde-se perceber um destaque dado pelas profissionais ao papel educativo que elas realizam junto a bebês e crianças pequenas. Contudo, este apareceu em algumas situações reduzido ao ensino e à transmissão de conhecimentos: "Procuro sempre ensinar o máximo que eu sei pras crianças" (EH5); "Eu tento adaptar atividades, trazer coisas diferentes, conhecimento pra eles" (EH6). Em meio a isso, as educadoras encontram-se algumas vezes concretizando um trabalho pedagógico bastante escolarizado, em que a criança tem que parar com o que está fazendo, sentar-se à mesa e realizar uma atividade proposta pela profissional: "Tem que sentar com eles na mesa, fazer o trabalho pedagógico" (EH1); "Nos momentos assim que eu posso ter mais contato com eles, na atividade na sala, na aula de produzir algum trabalhinho que depende mais da capacidade dele" (EH6).

Por meio das suas falas, as educadoras denunciaram um processo de antecipação do colégio já na Educação Infantil. Em parte, a escolarização da creche pode ocorrer pela função que ela adotou ao longo de sua história, visando, dentre outras coisas, diminuir o fracasso e o abandono escolar (Freitas \& Shelton, 2005; Freitas et al., 2008), preparando as crianças para o colégio e a aprendizagem (Dahlberg et al., 2001). Como resultado, essa visão de Instituição de Educação Infantil pode influenciar a organização das creches como uma escola, direcionando o foco das suas ações para o processo de ensino-aprendizagem (Elfer \& Page, 2015), letramento e construção do número (Goldschmied \& Jackson, 2004).

Contudo, os bebês e as crianças pequenas têm características e necessidades diferentes das crianças maiores, motivo pelo que a escola não seria adequada para cuidar e atender às demandas específicas dessa população (Cerisara, 1999). No que se refere ao trabalho com bebês, seria importante que não fosse atribuído muito destaque ao aspecto pedagógico, pois nesse momento o que o bebê precisa é de oportunidades adequadas para brincar e iniciar a sua vida social (Winnicott, 1965/2005), tendo o bebê e a criança pequena muito mais a ganhar do cuidado que lhes é ofertado do que da educação propriamente dita. Frente a isso, salienta-se a importância de deixar o ensino formal da criança para um período posterior (Winnicott, 1963/1983). Com isso, não se quer dizer que é negativo que haja uma organização pedagógica nas Instituições de Educação Infantil. Pelo contrário, é importante que haja tal organização, para que a função educativa das creches e pré-escolas não seja reduzida ao aspecto cognitivo do desenvolvimento, mas contemple também o aspecto social e o emocional, estando o educar em constante diálogo e integração com o cuidar.

Além disso, a ênfase do aspecto educativo nas creches pode ter ocorrido por outros motivos. Levando em consideração que o trabalho pedagógico e educacional retém maior valor profissional quando comparado aos demais papéis desempenhados pelo educador (Veríssimo \& Fonseca, 2003a, 2003b), o profissional pode achar necessário desenvolver atividades pedagógicas e dirigidas de ensino para se sentir valorizado e respeitado na sua profissão. Ao mesmo tempo, esse modelo de educação voltado para bebês e crianças pequenas - antecipando aprendizados e funções próprias do colégio - pode ser proveniente da crença de que fazer algo antes da idade esperada é bom para a criança (Lordelo \& Carvalho, 2003). Contudo, proporcionar experiências para as crianças 


\section{M." INTERACÃO EM PSICOLOGIA}

com as quais elas não se encontram ainda prontas para lidar, cobrando ou esperando delas algo para o qual elas não estão maturacionalmente preparadas, pode prejudicar o seu desenvolvimento. Nesse sentido, é importante não colocar as crianças numa posição muito avançada para elas, uma vez que as consequências disso podem ser desastrosas para o seu desenvolvimento (Winnicott, 1965/2005).

Por outro lado, é possível que o modelo de educação empregado nas Instituições de Educação Infantil seja tomado a partir do escolar por ser o único que as educadoras possuem. Assim, as profissionais podem não saber outra forma de trabalhar o aspecto educativo com crianças pequenas separado do modelo de colégio que elas provavelmente tiveram durante a sua própria escolarização e que aprenderam durante a faculdade, estando este muitas vezes restrito à alfabetização: "faltavam três semestres e eu tinha visto [durante a graduação] só alfabetização" (EU3); "Eu tive mais cadeiras sobre alfabetização na faculdade do que falaram de outras coisas" (EU6).

Como o modelo proveniente do colégio é inadequado para ser replicado nas Instituições de Educação Infantil, destaca-se a importância de que outro seja desenvolvido para se trabalhar com essa faixa etária, um que contemple e leve em consideração as especificidades características dos bebês e das crianças pequenas. Nesse contexto, faz-se necessário expandir o conceito de educação para que ele não se encontre mais reduzido simplesmente à escolarização, ou seja, ao ensino e ao desenvolvimento de atividades pedagógicas e dirigidas (Freitas \& Shelton, 2005). A educação precisa ser ampliada para englobar outros aspectos do desenvolvimento infantil - como o social, o emocional e o cultural - de modo que a criança seja vista além do seu desenvolvimento cognitivo.

Apesar disso, as educadoras demonstraram possuir, de modo geral, uma compreensão mais ampla de educação, envolvendo outros aspectos que não só o cognitivo, mas também o social, o emocional e o motor, os quais devem ser igualmente abordados e contemplados no trabalho com bebês e crianças pequenas: "A educação é muito importante. Pro desenvolvimento cognitivo, e até mesmo pro emocional também, porque vai aprender a socializar, a lidar com outras pessoas, a brincar" (EU4); “Estimular, estímulo. Em tudo assim, físico, emocional. A criança tenha sempre esse apoio, estímulo, assim, pra sempre ir conquistando as coisas" (EU7). Da mesma forma, o educar não ocorreria exclusivamente durante os momentos pedagógicos, nem unicamente através de atividades dirigidas. A educação da criança poderia acontecer em qualquer momento, uma vez que ela também aprende e se desenvolve quando está sendo cuidada, brincando e interagindo com outras crianças ou membros da equipe: "Qualquer momento que a gente tem ali com eles é um estímulo, é uma prática. Como nos momentos de higiene, de sono, de troca, sempre tudo. Acho que cada momento é pedagógico, é importante" (EU7); "Brincar, conviver. 0 próprio brincar favorece o convívio, eles aprendem, viram amigos. Aprendizagem é um resultado" (EU1). Esses achados mostram que em alguma extensão a necessidade de se reconceitualizar o educar (Freitas \& Shelton, 2005) já vem sendo alcançada em algumas creches e pré-escolas.

Dentre os outros modos de se desempenhar o papel educativo, o brincar foi destacado por algumas educadoras como a melhor forma que a criança teria para aprender e se desenvolver. Esse ponto merece destaque, tendo em vista que é através da brincadeira que a criança adquire experiência, desenvolve a sua personalidade e se organiza inicialmente para estabelecer relações emocionais e sociais (Winnicott, 1957/1982). Para Winnicott (1971/1975), o brincar é universal e próprio da infância, pois é através dele que a criança vai ter facilitado o seu crescimento e a sua saúde. Para o autor, o brincar é essencial. É no brincar que a criança desfruta, manifesta e desenvolve a sua capacidade de criação, descobrindo a si mesma, os outros e o mundo à sua volta. Também é o brincar que conduz a criança, pouco a pouco, para os relacionamentos grupais. Nesse sentido, permitir que a criança brinque seria uma das funções mais importantes da Educação Infantil: "acho que o brincar é tudo na Educação Infantil. A criança, ela desenvolve o conhecimento pra papel na sociedade, conflitos que ela vai ter, tem tudo ali no brinquedo" (EU3).

Entretanto, quando as educadoras passavam a falar mais especificamente do trabalho que desenvolviam com os bebês, a estimulação apareceu como uma forma de exercerem o papel educativo nas turmas de berçário: "A gente costuma botar eles [os bebês] no rolo pra estimular pra engatinhar. Colocar na sala, tem uma barra também. Aí a gente fica estimulando os sensoriais" (EH2); "Nós tinha todo um trabalho de estimulação com eles, desde bem novinhos, a gente ficava fazendo estimulação pra ele brincar, estimulação pra ele ir pro chão, pra caminhar mais adiante, começar a se soltar" (EH6). Através dessas falas, é possível inferir a crença de que os bebês precisariam ser estimulados para desenvolver as suas capacidades e potencialidades. Isso pode se dar, em parte, devido à ideia de que o bebê não aprende ou se desenvolve sem a intervenção e a orientação direta de um adulto, mais precisamente o professor (Lordelo \& Carvalho, 2003): “Ele [o bebê] tá pronto pras descobertas. Cabe a ti como educador saber de que forma vai conduzir essas descobertas dele. Primeiro, são as primeiras capacidades. Pode ser, cabe ao adulto. $\mathrm{O}$ adulto é responsável" (EH1).

A partir disso, pode-se inferir a compreensão do bebê enquanto passivo, o que aponta para a necessidade de se retrabalhar essa construção dentro das Instituições de Educação Infantil de forma que os bebês sejam percebidos como ativos no seu processo de aprendizagem e desenvolvimento. Nessa perspectiva, ao educador caberia - muito mais do 


\section{4* INTERACÃO EM PSICOLOGIA}

que conduzir e propor atividades - se deixar guiar pelo bebê, apoiando as suas novas descobertas e movimentos espontâneos. Para tanto, bastaria que o educador muitas vezes estivesse apenas presente e atento ao que é realizado pelo bebê (Dahlberg et al., 2001), funcionando como facilitador, ao invés de diretor (Goldschmied \& Jackson, 2004), isto é, como suporte para as atividades e iniciativas da criança: "Eu me vejo assim como professor artista. No sentido de criação, de querer que as crianças criem, eu acredito muito numa questão da descoberta delas, por elas mesmas. De instigar que elas busquem por si mesmas" (EU6). Nesse sentido, ao invés de estimular ou dirigir as atividades dos bebês, seria mais importante que a instituição proporcionasse um ambiente suficientemente bom (Winnicott, 1969/1994, 1987/2006), onde a criança se sinta segura para brincar, explorar e estabelecer relações com colegas e educadoras. Todavia, é importante lembrar que os bebês se encontram num estado de dependência absoluta (Winnicott, 1969/1994, 1987/2006) e que, portanto, dependem dos adultos responsáveis por cuidar deles para conhecer o mundo.

Aqui, é interessante ainda notar que o estimular recebeu maior destaque quando as educadoras estavam falando especificamente do trabalho realizado no berçário. Estimular o desenvolvimento de capacidades e habilidades principalmente motoras - como engatinhar, caminhar e segurar objetos - pode ter recebido um destaque por conduzir a uma maior independência do bebê. A maior autonomia do bebê pode ser bastante visada em um ambiente de cuidado coletivo, onde há um número maior de crianças do que de profissionais por sala. Nesse contexto, pode ocorrer de a profissional se deparar com uma situação em que há muitos bebês para serem atendidos ao mesmo tempo (Bógus et al., 2007; Bressani et al., 2007), devendo ela, portanto, estar atenta às necessidades de um grupo de crianças (Elfer, 2007). Desse modo, é compreensível que as educadoras valorizem o papel da estimulação junto aos bebês, uma vez que uma maior autonomia permitiria ao infante realizar algumas atividades - inclusive de cuidado básico - por conta própria ou com a supervisão de um adulto. Contudo, deve-se chamar a atenção para os riscos que uma estimulação ou treinamento precoce podem ter para os bebês, sendo inconveniente para o seu processo de desenvolvimento que eles amadureçam muito cedo numa idade em que deveriam ainda ser dependentes. Dessa forma, é recomendável que os bebês e as crianças pequenas não sejam postos numa posição muito avançada para eles, tendo em que vista que isso pode acarretar efeitos negativos para o seu desenvolvimento (Winnicott, 1965/2005).

Por outro lado, o cuidar também figurou como uma das funções desempenhadas pelas educadoras: "Cuidado, ressalta o cuidado porque a criança às vezes tá xixi, tá cocô, tem que verificar. Se a criança tá comendo bem" (EU4); "Olha, tem que
Rodrigo Gabbi Polli e Rita de Cassia Sobreira Lopes ter os cuidados básicos, alimentação, higiene, saúde. Precisa pra ele ficar bem" (EU5). Ao se trabalhar com bebês e crianças pequenas, o cuidar se impõe enquanto uma das funções que necessariamente precisam ser integradas, devido inclusive à própria especificidade da faixa etária, tendo em vista que o bebê e a criança pequena são percebidos como dependentes de cuidados para que possam se desenvolver de modo saudável (Vitta \& Emmel, 2004). Isso decorre do fato de o bebê - por ser ainda muito imaturo - não conseguir dar conta das suas necessidades por si só. Ele é totalmente dependente de um adulto responsável que, ao reconhecer o estado de dependência do bebê, se dedique a prover os cuidados que este necessita. São esses cuidados, disponibilizados pelo adulto de maneira sensível e adaptada às necessidades da criança, que vão possibilitar que o bebê tenha um desenvolvimento saudável e se torne - num primeiro momento - relativamente dependente para, em seguida, ir rumo à independência (Winnicott, 1969/1994, 1987/2006).

Contudo, quando as educadoras falaram sobre o cuidar, esse surgiu principalmente voltado para atender às necessidades básicas dos bebês: "quando eu falo cuidado, especialmente aqui, que é um número grande de crianças, é o cuidado de não se machucar, de experimentar sem que isso vá prejudicar ele, a criança no sentido até físico mesmo" (EU8). Através dessa fala, ainda é possível pensar o quanto um "número grande de crianças" (EU8) para um número menor de profissionais em parte dificulta que outro tipo de cuidado - mais sutil, emocional - seja ofertado nas Instituições de Educação Infantil.

Estudos têm mostrado que a razão adulto-criança é um dos fatores que influenciam diretamente as ações educativas e de cuidado no cotidiano das creches (Bógus et al., 2007; Bressani et al., 2007; Elfer, 2015; Hopkins, 1990; Vitta \& Emmel, 2004). Inclusive, um dos motivos associados a um cuidado impessoal e distante é a proporção educador-criança inadequada, a qual não permite que relacionamentos íntimos e próximos sejam estabelecidos (Hopkins, 1990). Nesse sentido, é possível pensar que uma razão adulto-criança suficiente facilite que um cuidado sensível e adequado seja disponibilizado para os bebês que frequentam o berçário, apontando para a importância desse fator na promoção da qualidade do atendimento nas Instituições de Educação Infantil (Bressani et al., 2007; Elfer, 2015). Dentro desse contexto, em salas com muitas crianças, talvez o "cuidado mesmo, assim, da questão mais física" (EU8) seja o que é muitas vezes possível alcançar ou posto como mais urgente de ser atendido, tendo em vista que, em algumas ocasiões, há muitos bebês para serem atendidos ao mesmo tempo (Bógus et al., 2007; Bressani et al., 2007). Nesse sentido, as necessidades imediatas das crianças podem sobressair-se sobre as demais, principalmente quando acompanhadas pelo choro forte (Lordelo, 1998). 


\section{M." INTERACÃO EM 4T PSICOLOGIA}

Embora a compreensão de cuidado tenha aparecida limitada ao atendimento das necessidades básicas, foi possível perceber que as educadoras geralmente buscam desempenhá-lo de modo afetivo, fazendo com que os momentos de cuidado fossem além de uma função simplesmente física, mas adquirissem certa qualidade:

vai trocar, pode ser só cuidado, chega lá, coloca o bebê no trocador e abrir as fraldas. Ou pode ser uma brincadeira, ir conversando, ir colocando a perninha, ir brincando na barriga, ir conversando com ele, fazendo com que aquilo seja prazeroso pra ele se divertir. É uma troca. Acho que tem que ter troca (EU6).

Apesar de as educadoras não terem considerado que estabelecer um contato próximo e afetivo - brincando, conversando ou cantando para a criança - faz parte do cuidar, elas reconheceram que, para além das necessidades básicas, os bebês teriam outro tipo de necessidade: "Acho que um bebê necessita não só as necessidades físicas dele. Não pode pegar o bebê só pra alimentar, trocar a fraldinha, não sei o quê. Não o tempo acho que só pras necessidades biológicas" (EH1). Nesse sentido, além dos cuidados físicos, a criança precisaria de outra coisa, algo descrito pelas educadoras como sendo da ordem do relacionamento que o educador estabelece com o bebê: "Eu acho que tem que dar carinho, acho que na infância é fundamental aquele afeto, acolhimento. Carinho de quem tá te cuidando" (EH4); "Atenção, eu em relação às crianças. $E$ afeto pro desenvolvimento deles" (EU1).

Embora haja, de modo geral, na Educação Infantil uma cultura que preza e prioriza a educação das crianças frente a outras funções que a creche tem a cumprir (Elfer, 2007, 2015; Veríssimo \& Fonseca, 2003a, 2003b), algumas educadoras relataram a importância do relacionamento afetivo e do ambiente adequado como algo que deveria ser priorizado e, portanto, alcançado antes que outras tarefas - como as educativas ou de estimulação - fossem postas em prática: "Muito estímulo. $E$ antes do estímulo acho que também um ambiente alegre. As pessoas que trabalham com isso têm que mostrar muita alegria, satisfação em estar com aquela criança. Pra aquele bebê saber que é amado e estar feliz" (EH2); "Dá muito carinho pra criança naquele momento que ela tem que se apegar com a gente. Depois o todo, a parte cognitiva, motora" (EH5). Nesse sentido, é muito positivo que as educadoras tenham dado atenção ao aspecto emocional e à qualidade do ambiente da creche - no sentido de cuidado e relacionamento educador-criança -, uma vez que as tendências inatas da criança ao desenvolvimento obtêm resultados satisfatórios somente quando ela é amparada por um ambiente de facilitação suficientemente bom (Winniccot, 1969/1994, 1987/2006).

Ainda no que diz respeito ao relacionamento que o profissional estabelece com os infantes, também se destacou
Rodrigo Gabbi Polli e Rita de Cassia Sobreira Lopes

a importância do contato físico, corporal e do toque, sendo necessário que em alguns momentos o educador inclusive segure a criança no colo: "E às vezes assim é o toque, a massagem na barriga. Eles [os bebês] ficam bem contentes" (EH2); "Muito aconchego, muito afeto. Muito trazer pra ti. A questão do toque é muito importante" (EH3). A partir disso, pode-se perceber que, para essas profissionais, o contato físico é fundamental quando se está trabalhando com bebês e crianças pequenas, sobretudo quando se tem em mente que o relacionamento e a comunicação com essa faixa etária se dá de outras formas que não só pela linguagem verbal. Levando em consideração o que Winnicott (1987/2006) disse sobre os bebês, a comunicação entre o bebê e o seu cuidador é silenciosa, podendo o adulto falar ou não, uma vez que é o cuidado suficientemente bom que vai transmitir para o bebê a confiabilidade de cuidados. Além disso, o contato humano comunica ao bebê toda a vivacidade que há no ambiente, atendendo à demanda do infante de não ser deixado sozinho com seus próprios recursos, quando estes ainda se encontram muito imaturos (Winnicott, 1969/1994, 1987/2006).

Aqui, vale ainda destacar que uma visão simplista sobre o cuidado, como se este constituísse um trabalho simplesmente manual e prático (Veríssimo \& Fonseca, 2003a, 2003b), não foi identificada neste estudo, tendo em vista que as educadoras relataram desenvolver as tarefas de cuidado físico de modo afetivo, dedicando-se às crianças durante o tempo em que estavam com elas. Contudo, como o cuidado foi em alguma medida reduzido ao atendimento das necessidades básicas da criança, destaca-se a importância de se reconceitualizar o cuidar e se transformar a cultura construída em torno dele (Freitas \& Shelton, 2005) para que o cuidado não seja limitado ao atendimento das necessidades do corpo da criança nem seja percebido como um trabalho simplesmente manual e de menor valor profissional.

Entretanto, perceber o cuidado como reduzido ao atendimento das necessidades básicas da criança pode exercer uma função importante dentro das Instituições de Educação Infantil. Uma vez que essa forma de pensar o cuidado pode autorizar o educador a se relacionar apenas com o corpo da criança - ou uma parte deste -, ele não precisaria, sobretudo nos momentos de cuidado, interagir ou se envolver emocionalmente com ela. Nesse sentido, reduzir o cuidado ao atendimento das necessidades físicas pode ser uma forma de os educadores se manterem afastados e se protegerem de entrar em contato com os sentimentos oriundos do convívio direto com bebês e crianças pequenas, uma vez que o trabalho com essa faixa etária pode provocar ou despertar no profissional uma variedade de emoções muitas vezes difícil para o educador dar conta sozinho (Cardenal, 2011; Elfer, 2007, 2015; Hopkins, 1990; Polli \& Lopes, 2017). Como essa compreensão do cuidado pode se fazer presente e, portanto, atrapalhar o re- 


\section{M." INTERACÃO EM PSICOLOGIA}

lacionamento e a interação educador-criança, é fundamental que espaços de escuta sejam ofertados dentro das Instituições de Educação Infantil para os profissionais que compõem suas equipes. Esses espaços, que podem ser disponibilizados na forma de grupos de supervisão ou reflexão profissional (Elfer, 2015; Hopkins, 1990), objetivam que questões que entravam o estabelecimento de um vínculo próximo e afetivo do educador com as crianças sejam verbalizadas e trabalhadas.

No que se refere ao cuidado e ao tipo de relacionamento que o educador estabelece com as crianças, o trabalho exercido dentro das Instituições de Educação Infantil foi em parte associado à função materna, ou seja, um papel originalmente pertencente ao contexto familiar: "sempre pensei em fazer pelos filhos dos outros o que eu gostaria que fizessem pros meus. Então, eu trabalho mais ou menos assim" (EH3); "Eu acho que tem que dar carinho, acho que na infância é fundamental, aquele afeto, acolhimento, de ter aquele carinho, aquele amor de mãe. Carinho de quem tá te cuidando" (EH4). A partir disso, se torna evidente o quanto - para algumas educadoras - o trabalho que elas realizam se aproxima da função materna. Nesse sentido, elas trazem para a sua prática elementos ou modos de interagir com a criança que na sua concepção seriam próprios ou oriundos do contexto familiar e da relação mãe-bebê, como o "carinho" e o "amor de mãe" (EH4). Essa forma de perceber o trabalho dentro de creches e pré-escolas corresponderia à visão de Instituição de Educação Infantil enquanto um lar substituto, o qual deveria proporcionar para as crianças relacionamentos próximos e íntimos com os funcionários. Dessa forma, como é esperado que esses serviços se aproximem do modelo de cuidado materno ou familiar (Dahlberg et al., 2001; Elfer \& Pages, 2015), isso contribuiria para a produção de uma força de trabalho predominantemente feminina (Dahlberg et al., 2001).

Tendo em vista as duas principais funções exercidas pelas educadoras, algumas profissionais mencionaram integrar o educar e o cuidar no seu trabalho:

Acho que contato, contato físico. Tu canta, tu estimular aquela criança a engatinhar, pegar objetos. Mas sempre em contato de segurar, de beijar. Tu vê que eles necessitam disso. Não, tu larga no chão, ah, deu. Não. Eu acho que tá em contato ali, até na alimentação, não é aquela coisa de pegar, 'Oh, tá na hora de comer'. Não. Tu conversa, tu explica (EH4).

Através dessa fala, é possível refletir o quanto essa educadora integra e conecta os seus papéis no contato que ela estabelece com os bebês e as crianças. Nesse sentido, o trabalho dessa profissional não parece separado ou fragmentado em momentos educativos e momentos de cuidado, uma vez que ambas as funções ocorrem juntas; uma possibilitando, provocando e apoiando a outra. Resultados semelhantes foram encontrados em outro estudo (Monção, 2015), no qual as professoras compreenderam o Centro de Educação Infantil enquanto um espaço onde o cuidado e a educação são integrados. Apesar de esses exemplos apontarem que em alguma extensão a integração entre o cuidar e o educar - destacada como fundamental pela literatura (Elfer, 2007; Freitas \& Shelton, 2005; Freitas et al., 2008) - tem sido alcançada dentro de algumas Instituições de Educação Infantil, é importante notar que essa articulação parece ocorrer principalmente em um único sentido, havendo uma maior ênfase de que o trabalho pedagógico aconteça em todos os momentos, inclusive nos de cuidado básico:

Qualquer momento que a gente tem com eles [os bebês] é um estímulo, é uma prática. Tanto nessas atividades que a gente procura assim de estímulo do motor, tanto pra engatinhar, quanto pra já ficar firme, sentar. Como nos momentos de higiene, de sono, de troca, sempre tudo. Acho que cada momento é pedagógico, é importante (EU7).

A partir disso, pode-se perceber que há predominantemente uma integração da tarefa educativa nos momentos de cuidado, não ocorrendo com tanta ênfase uma busca de trazer o cuidado - ou uma postura relacionada ao cuidar para as atividades pedagógicas. Outros estudos (Bógus et al., 2007; Veríssimo \& Fonseca, 2003b) também identificaram que algumas educadoras definem o cuidar como um momento de aprendizado, considerando que, durante os períodos de brincadeira, banho, alimentação, troca de fralda e roupa, a educadora, ao mesmo tempo em que cuida, está educando e a criança aprendendo.

Essa integração parcial das funções das educadoras pode se dar já que elas não saberiam como integrá-las. Frente a isso, destaca-se novamente a importância de se reconceitualizar tanto o cuidar como o educar (Freitas \& Shelton, 2005), uma vez que uma compreensão mais ampla e abrangente dessas funções poderia permitir que as educadoras pensassem formas de integrá-las no seu fazer. No entanto, atingir esse objetivo de não apenas integrar o cuidar e o educar, mas também que ambas as funções sejam igualmente valorizadas nos serviços voltados à infância, pode ser bastante complicado, uma vez que algumas educadoras querem ser reconhecidas pelo seu papel educativo, e não pelo cuidado que elas disponibilizam para as crianças:

O que mais dificulta pra gente é, a gente tem um estatuto, tem isso como regras, e essas regras são quebradas. Pelos pais. Porque infelizmente eles ainda veem isso aqui não como uma instituição educacional, eles veem isso aqui como uma instituição cuidadora. A gente fala: "Tu sabia que teu filho tá pintando, teu filho tá fazendo isso, tá fazendo aquilo?", "Ah, eu não sabia. Ele comeu, ele fez xixi, ele fez cocô?" Sabe? A coisa sempre puxa mais pro lado 


\section{H. INTERACÃO EM PSICOLOGIA}

do cuidado pessoal do que pro lado intelectual. Eles enxergarem a gente não como professora nem educadora, não precisa que me chame de professora, mas eles continuam achando que nós somos babás (EH6).

0 fato de os pais não seguirem as regras impostas pela instituição denuncia para a profissional uma desvalorização da creche enquanto instituição de educação. 0 mesmo foi identificado em um Centro de Educação Infantil (CEI) da rede municipal de São Paulo, no qual as professoras interpretavam a dificuldade das famílias de cumprirem os horários da creche como uma desvalorização do papel educacional do CEI (Monção, 2015). Embora algumas funcionárias tentem chamar a atenção dos pais para os aspectos educacionais dos filhos, estes por sua vez se interessam mais pelo cuidado, percebendo - na opinião das educadoras - a creche enquanto instituição destinada ao cuidar, não tanto ao ensino e à aprendizagem. Talvez isso seja um reflexo do que os pais julgam ser mais importante para um bebê ou uma criança pequena, ou seja, o cuidado. Como consequência, as profissionais podem se sentir frustradas, uma vez que o seu trabalho como educadoras não é tão valorizado pelos pais, mas sim o seu papel como cuidadoras. Nesse contexto, chama a atenção um estudo realizado no Rio de Janeiro (Pessôa, Seidl-de-Moura, Ramos, \& Mendes, 2016), o qual evidenciou que as mães e as educadoras de creche parecem ter discursos semelhantes quanto ao que valorizam no cuidado disponibilizado aos bebês, priorizando o contato corporal (por exemplo: segurar o bebê no colo) e interações face-a-face (por exemplo: manter contato pelo olhar). Apesar disso, mães e educadoras apresentaram algumas diferenças em relação aos cuidados básicos e ao contato corporal, com as mães valorizando mais as trocas de carinhos e afetos nesses momentos, e as educadoras se preocupando mais em atender as necessidades básicas do bebê. Ao mesmo tempo, é possível pensar também o quanto dentro do campo da Educação o trabalho direto com os bebês e as crianças pequenas - principalmente quando envolve cuidados físicos, como a troca de fraldas - pode ser visto com status inferior (Elfer \& Dearnley, 2007).

\section{CONSIDERAÇÕES FINAIS}

Os resultados do presente estudo possibilitaram pensar que um movimento de escolarização - ou de antecipação do colégio - pode estar acontecendo em algumas Instituições de Educação Infantil do Brasil. Contudo, os bebês e as crianças pequenas possuem características e necessidades diferentes das crianças maiores, motivo pelo qual o modelo de escola não é adequado para atender essa população. Frente a isso, é importante se pensar um novo modelo de atuação para as creches que contemple as especificidades dos bebês e das crianças pequenas. Devido à fase do desenvolvimento em que estes se encontram, seria muito mais interessante que as Instituições de Educação Infantil se organizassem de forma a atribuir maior importância ao cuidado e à qualidade do relacionamento educador-criança. Nesse momento, o ensino propriamente dito deveria ser deixado para uma fase posterior. Nesse novo modelo de creche, o educador - muito mais do que ensinar ou propor atividades - funcionaria enquanto facilitador das iniciativas espontâneas da criança e promotor de um ambiente satisfatório em que ela se sinta segura para brincar, explorar e se relacionar com as outras crianças e membros da equipe. Para tanto, é fundamental que as educadoras sejam assistidas por um profissional da Psicologia, por exemplo, através da oferta de espaços de escuta nas próprias instituições, em função das exigências emocionais envolvidas no seu trabalho.

Além disso, uma reconceitualização do cuidar e do educar se faz necessária para que o cuidado não se encontre reduzido ao atendimento das necessidades básicas das crianças, nem a educação esteja limitada ao ensino e ao desenvolvimento cognitivo. Espera-se que uma compreensão mais ampla e abrangente dessas funções possa facilitar que a necessária integração entre cuidar e educar seja alcançada. Além disso, acredita-se que se o educar for implementado e considerado no seu sentido mais amplo - isto é, englobando o desenvolvimento cognitivo, emocional, motor e social da criança -, ele pode se constituir enquanto uma prática de cuidado. Isso se deve ao fato de que um entendimento mais abrangente do educar, ao invés de fragmentar o bebê, promoveria o seu desenvolvimento integral nos seus mais diversos aspectos.

Vale ainda destacar que, apesar do movimento de escolarização da creche, tanto o cuidar quanto o educar foram reconhecidos pelas educadoras como importantes. Nesse sentido, as profissionais não trouxeram as suas funções de forma tão polarizada quanto a literatura aponta. Muito mais do que valorizar apenas o cuidar ou apenas o educar, as educadoras pareceram adotar uma posição intermediária, buscando integrar as suas funções. Aqui, é importante ter em mente que a creche no Brasil mudou recentemente do campo da Assistência Social para o da Educação. Dessa forma, as falas das educadoras parecem refletir o momento de transição em que as creches se encontram.

Importante destacar também que os resultados do presente estudo podem se encontrar limitados ao contexto específico das participantes, as quais são educadoras de creches pertencentes a instituições públicas federais de Porto Alegre/ RS. Nesse sentido, sugere-se a realização de outros estudos que investiguem o que é ser educador infantil na perspectiva das educadoras em diferentes contextos e regiões do Brasil. Apesar disso, o presente estudo traz diversas contribuições importantes para a compreensão do trabalho realizados pelas educadoras nas Instituições de Educação Infantil, e seus 


\section{M." INTERACÃO EM PSICOLOGIA}

resultados podem ser utilizados para embasar estratégias de intervenção junto às equipes de creches e pré-escolas.

\section{DECLARAÇÃO DA CONTRIBUIÇÃO DOS AUTORES}

Certificamos que todos os autores participaram suficientemente do trabalho para tornar pública sua responsabilidade pelo conteúdo. A contribuição de cada autor pode ser atribuída como se segue:

R. G. P. e R. C. S. L. contribuíram para a conceitualização, metodologia e visualização do artigo; R. G. P. foi responsável pela análise formal dos dados e redação do artigo; e R. C. S. L. foi a responsável pela supervisão.

\section{FINANCIAMENTO}

A pesquisa relatada no manuscrito foi financiada pela bolsa de doutorado sanduíche do primeiro autor (Bolsista da CAPES - Proc. $n^{\circ}$ BEX 8327/14-9).

\section{DECLARAÇÃO DE CONFLITOS DE INTERESSE}

Os autores declaram que não há conflitos de interesse no manuscrito submetido.

["Impacto da creche no desenvolvimento socioemocional e cognitivo infantil: estudo longitudinal do sexto mês de vida do bebê ao final dos anos pré-escolares" - CRESCI (Piccinini et al., 2012), o qual ainda está em andamento. O CRES$\mathrm{Cl}$ está registrado na Plataforma Brasil sob protocolo CAAE 15840313.0.0000.5334]

[CRESCI]

[CRESCI]

[Universidade Federal do Rio Grande do Sul (Protoc. N ${ }^{\circ}$ 2010070)]

[Hospital de Clínicas de Porto Alegre (Protoc. № 100553)]

[Polli \& Lopes, 2017]

[Piccinini, C. A., Lopes, R. C., Sperb, T., Gabriel, M., Polli, R. G., Becker, S. M. S, ... Bossi, T. (2012). "Impacto da creche no desenvolvimento socioemocional e cognitivo infantil: estudo longitudinal do sexto mês de vida do bebê ao final dos anos pré-escolares" - CRESCI. Projeto não-publicado, Instituto de Psicologia, Universidade Federal do Rio Grande do Sul, Porto Alegre.]

[Polli, R. G.; \& Lopes, R. C. S. (2017). Do que o bebê precisa? A função de cuidar na perspectiva das educadoras de berçário. Interação em Psicologia, 21(2), 157-166. http://dx.doi. org/10.5380/psi.v21i2.47810]

\section{REFERÊNCIAS}

Bógus, C. M., Nogueira-Martins, M. C. F., Moraes, D. E. B., \& Taddei, J. A. A. C. (2007). Cuidados oferecidos pelas creches: Percepções de mães e educadoras. Revista de Nutrição, 20(5), 499-514. http://dx.doi.org/10.1590/S141552732007000500006

Bressani, M. C. L., Bosa, C. A., \& Lopes, R. S. (2007). A responsividade educadora-bebê em um berçário: Um estudo exploratório. Revista Brasileira de Crescimento e Desenvolvimento Humano, 17(3), 21-36.

Cardenal, M. (2011). Psychoanalytic thinking in the communitys through Bick's observational method: A work discussion seminar experience with care workers in a nursery. International Journal of Infant Observation and Its Applications, 14(3), 245-255. http://dx.doi.org/10.1080/13698 036.2011 .616293

Cerisara, A. B. (1999). Educar e cuidar: por onde anda a educação infantil? Perspectiva, 17(número especial), 11-22.

Conselho Nacional de Saúde (2016). Resolução nº 510 de 07 de abril de 2016. http://conselho.saude.gov.br/resolucoes/2016/Reso510.pdf

Dahlberg, G., Moss, P., \& Pence, A. (2001). Beyond quality in early childhood education and care: postmodern perspectives. Routledge Falmer.

Elfer, P. (2007). Babies and young children in nurseries: Using psychoanalytic ideas to explore tasks and interactions. Children \& Society, 21(2), 111-122. http://dx.doi.org/10.1111/j.1099-0860.2006.00034.x

Elfer, P. (2015). Social defences in nurseries and the contemporary value of the concept. Em D. Armstrong \& M. Rustin, Social defences against anxiety: explorations in a paradigm (pp. 284-299). Karnac Books.

Elfer, P., \& Dearnley, K. (2007). Nurseries and emotional well-being: Evaluating an emotionally containing model of professional development. Early Years, 27(3), 267-279. http://dx.doi.org/10.1080/09575140701594418

Elfer, P., \& Page, J. (2015). Pedagogy with babies: Perspectives of eight nursery managers. Early Child Development and Care, 185(11-12), 1-21. http://dx.doi.org/10.1080/030044 30.2015 .1028399

Freitas, L. B. L., \& Shelton, T. L. (2005). Atenção à primeira Infância nos EUA e no Brasil. Psicologia: Teoria e Pesquisa, 21(2), 197-205. https://doi.org/10.1590/S010237722005000200010

Freitas, L. B. L., Shelton, T. L., \& Tudge, J. R. H. (2008). Conceptions of US and Brazilian early childhood care and education: A historical and comparative analysis. International Journal of Behavioral Development, 32(2), 161-170. http:// dx.doi.org/10.1177/0165025407087216 


\section{INTERACÃO EM LFICOLOGIA}

Goldschmied, E., \& Jackson, S. (2004). People under three: Young children in day care. ( $2^{\text {nd }}$ ed.). Routledge.

Hopkins, J. (1990). Facilitating the development of intimacy between nurses and infants in day nurseries. Em A. S. Honig, Optimizing Early Child Care and Education: Special aspects of education (Vol. 13, pp. 99-111). Gordon and Breach Science Publichers.

Instituto Nacional de Estudos e Pesquisas Educacionais Anísio Teixeira - INEP (2014). Censo escolar da educação básica 2013: resumo técnico. INEP.

Laville, C., \& Dionne, J. (1999). A construção do saber: manual de metodologia da pesquisa em ciências humanas. Artes Médicas.

Lordelo, E. R. (1998). Educadoras de creche: concepções e práticas. Interação em Psicologia, 2, 113-132. http://dx. doi.org/10.5380/psi.v2i1.7650

Lordelo, E. R., \& Carvalho, A. M. A. (2003). Educação Infantil e Psicologia: para que brincar? Psicologia Ciência e Profissão, 23(2), 14-21. http://dx.doi.org/10.1590/S141498932003000200004

Monção, M. A. G. (2015). O compartilhamento da educação das crianças pequenas nas instituições de educação infantil. Cadernos de Pesquisa, 45(157), 652-679. http://dx. doi.org/10.1590/198053143052

Pessôa, L. F., Seidl-de-Moura, M. L., Ramos, D. O., \& Mendes, D. M. L. F. (2016). Sistemas de cuidados e o discurso de diferentes cuidadores do Rio de Janeiro: Evidências de trajetória de desenvolvimento. Estudos de Psicologia, 33(1), 71 82. http://dx.doi.org/10.1590/1982-02752016000100008

Piccinini, C. A., Lopes, R. C., Martins, G. D. F., Becker, S. M. S, Sperb, T., Gabriel, M., Polli, R. G., Bortolini, M., Cherer, E. \& Bossi, T. J. (2012). "Impacto da creche no desenvolvimento socioemocional e cognitivo infantil: estudo longitudinal do sexto mês de vida do bebê ao final dos anos pré-escolares" - CRESCI. [Projeto não-publicado]. Instituto de Psicologia, Universidade Federal do Rio Grande do Sul, Porto Alegre. http://www.ufrgs.br/psicologia/nucleos-e-laboratorios/ nudif/projetos-de-pesquisa/2010-atual-impacto-da-creche-no-desenvolvimento-socio-emocional-e-cognitivo-infantil-estudo-longitudinal-do-primeiro-ao-segundo-ano-de-vida-da-crianca-cresci

Polli, R. G.; \& Lopes, R. C. S. (2017). Do que o bebê precisa? A função de cuidar na perspectiva das educadoras de berçário. Interação em Psicologia, 21(2), 157-166. http://dx.doi. org/10.5380/psi.v21i2.47810
Presidência da República, Casa Civil, Subchefia para Assuntos Jurídicos. (1996). Lei 9.394: Estabelece as diretrizes e bases da educação nacional. http://www.planalto.gov.br/ ccivil_03/leis/l9394.htm

Stake, R. E. (1994). Case studies. Em N. Denzin \& Y. Lincoln (Orgs.), Handbook of qualitative research (pp. 236-247). Sage.

Veríssimo, M. D. L. O. R., \& Fonseca, R. M. G. S. (2003a). Funções da creche segundo suas trabalhadoras: Situando o cuidado da criança no contexto educativo. Revista da Escola de Enfermagem, 37(2), 25-34. http://dx.doi. org/10.1590/S0080-62342003000200004

Veríssimo, M. D. L. O. R., \& Fonseca, R. M. G. S. (2003b). 0 cuidado da criança segundo trabalhadoras de creches. Revista Latino-Americana de Enfermagem, 11(1), 28-35. http://dx.doi.org/10.1590/S0104-11692003000100005

Vitta, F. C. F., \& Emmel, M. L. G. (2004). A dualidade cuidado $\mathrm{x}$ educação no cotidiano do berçário. Paidéia, 14(28), 177-189. http://dx.doi.org/10.1590/S0103$863 \times 2004000200007$

Winnicott, D. W. (1975). O brincar e a realidade. Imago. (TrabaIho original publicado em 1971).

Winnicott, D. W. (1982). Por que as crianças brincam. Em Winnicott, D. W., A criança e o seu mundo (pp. 161-165). LTC Editora. (Trabalho original publicado em 1957).

Winnicott, D. W. (1983). Moral e educação. Em Winnicott, D. W., 0 ambiente e os processos de maturação: estudos sobre a teoria do desenvolvimento emocional (pp. 88-98). Artmed. (Trabalho original publicado em 1963).

Winnicott, D. W. (1994). A experiência mãe-bebê de mutualidade. Em Winnicott, D. W., Explorações psicanalíticas (pp. 195-202). Artmed. (Trabalho original publicado em 1969).

Winnicott, D. W. (2005). A família e o desenvolvimento individual. Martins Fontes. (Trabalho original publicado em 1965)

Winnicott, D. W. (2006). Os bebês e suas mães. Martins Fontes. (Trabalho original publicado em 1987).

Submetido em: 06/06/2018 Primeira decisão em: 09/04/2020 Segunda decisão em: 14/04/2020 Aceito em: 11/05/2020 